\title{
Distributed Morphology of Akan-Twi Plurals
}

\section{Emmanuel Amo Ofori}

Department of Ghanaian Languages and Linguistics, University of Cape Coast, Cape Coast, Ghana

Email address:

eofori@ucc.edu.gh

\section{To cite this article:}

Emmanuel Amo Ofori. Distributed Morphology of Akan-Twi Plurals. International Journal of Language and Linguistics. Vol. 4, No. 2, 2016, pp. 57-60. doi: 10.11648/j.ij11.20160402.12

\begin{abstract}
Following the discussions of Bodomo and Marfo's (2002) morphophonological analysis of Akan and Dagaare noun class system using number marking: singular and plural within Lexical Phonology theoretical framework, the present study seeks to provide a broader analysis of Akan-Twi plurals based on Distributed Morphology theoretical framework provided by Halle and Marantz $(1993,1994)$. The core issue of this paper is to account for whether the attachment of the prefix $a$ - and the suffix -for on some stems in Akan is due to the spell-out of vocabulary item (VI) or due to other morphological operations such as fission. Moreover, the paper attempts to address the context in which the Vocabulary Item /a-/ applies.
\end{abstract}

Keywords: Distributed Morphology, Akan-Twi, Plurals, Vocabulary Insertion, Fission

\section{Introduction}

This paper concentrates on the Distributed Morphology of Akan-Twi plurals. Akan is a language which belongs to the Kwa sub-group of Niger-Congo family of West Africa, spoken in Ghana. Number is shown in Akan based on singular and plural dichotomy. There have been various attempts to analyze Akan plurals focusing on semantic criterion. Bodomo and Marfo's (2002) recent proposal on the morphophonology of noun class system in Dagaare and Akan shows that the most appropriate criterion that can be used to set up noun classes is number- i.e. singular and pluralcategorization. This is marked mainly by suffixes in Dagaare and in Akan by prefixes. Indeed, Akan also manifests the use of suffixes to show plurality. They therefore put nouns in Akan and Dagaare into classes based on the similarity of both the singular and plural affixes. With this criterion, nouns are always in the same class, whether in the singular or plural. That is to say, nouns in the same class must have similar singular affixes and similar plural affixes. Apart from classifying the nouns based on affixation, they also relied heavily on phonological process to refine their classification. Ten (10) and nine (9) class systems were proposed in Akan and Dagaare respectively. Since the analysis of this paper is primarily on Akan plurals, I will focus only on data and analysis of Akan as proposed by Bodomo and Marfo (2002). Below is the nine-class system of Akan shown in table 1 .

The noun class system of Akan is based mainly on an interface between the morphological and phonological components of the grammar, thus the basic assumption with regard to their analysis is mainly phonological. They further intimated that due to the preference involved in the selection of a particular affix, the morphological facts cannot satisfactorily explain their criterion, and therefore appealed to phonological information. The most prominent of the phonological information is the advanced tongue root (ATR) vowel harmony principle. By the vowel harmony principle, the assumption is that the ten vowels in Akan fall into two phonetically distinctive classes; i.e., a vowel is either produced with an advanced tongue root $([+\mathrm{ATR}] ;$ i $, \mathrm{e}, \mathrm{o}, \mathrm{u}, æ /)$ or with a retracted tongue root $([-\mathrm{ATR}] ; / 1, \varepsilon, \mathrm{a}, \mathrm{\rho}, \mathrm{v} / \mathrm{)}$. Following the distinction, all stem vowels are required to be of a common ATR feature specification. The ATR specification in the stem then dictates that of the vowels in the affixes. In this case, stem vowels that are [+ATR] select the same vowel specification in the affix and likewise [-ATR] stem vowels. This explains the differences between the prefix in $\varepsilon-k v$ o "buffalo" and $e-k u o$ "group". There are a few exceptional cases though, where both specifications occur in a word.

Indeed, it must be mentioned that Bodomo and Marfo's analysis was theoretical grounded in lexical phonology (LP) developed by Kiparsky (1985) and Mohana (1986). The aim of this study, however, is not to contradict Bodomo and Marfo's analysis of noun class system of Akan, but rather to give an alternative theoretical basis, in this case Distributed Morphology, for analyzing plural formation in Akan. It must also be mentioned that their analysis serves as background knowledge for the analysis of plural formation in Akan. 
Table 1. Noun Class system in Akan (Bodom and Marfo, 2002).

\begin{tabular}{|c|c|c|c|}
\hline Classes & Singular Form & Stem & Plural Fom \\
\hline 1 & \multicolumn{2}{|l|}{ V- } & \multirow{3}{*}{$\begin{array}{l}\mathrm{N}- \\
\text { mmaa 'females' } \\
\text { nkwaduo 'antelopes' }\end{array}$} \\
\hline a $0-\mathrm{N}-$ & sbaa 'famale' & -baa & \\
\hline a. $0-/ N-$ & skwaduo 'antelope' & -kwaduo & \\
\hline \multirow{2}{*}{ b. A- $/ \mathrm{N}-$} & ataade 'cloth' & -taade $\varepsilon$ & \multirow{2}{*}{$\begin{array}{l}\text { ntaadee 'clothes' } \\
\text { nkuma 'axes' }\end{array}$} \\
\hline & akuma 'axe & -kuma & \\
\hline \multirow{2}{*}{ c. (V)-/N- } & okraman 'dog' & -kraman & \multirow{5}{*}{$\begin{array}{l}\text { nkraman 'dogs } \\
\text { nnua 'trees' } \\
\text { mmepo mountains' } \\
\text { nsafoa 'keys' } \\
\text { A- }\end{array}$} \\
\hline & edua 'tree' & -dua & \\
\hline 2: Ø- / N- & beps 'mountain' & -bepo & \\
\hline & safoa 'key’ & -safoa & \\
\hline 3. & V- & & \\
\hline \multirow{2}{*}{ a. O- o/ A- } & shini 'king' & -hini & \multirow{2}{*}{$\begin{array}{l}\text { ahini 'kings' } \\
\text { apuro ‘squirrels' }\end{array}$} \\
\hline & opuro 'squirrel' & -puro & \\
\hline \multirow{2}{*}{ b. (V)- /A- } & efie 'house' & - fie & \multirow{2}{*}{$\begin{array}{l}\text { afie 'houses' } \\
\text { akuo 'groups' }\end{array}$} \\
\hline & ekuo 'group’ & -kuo & \\
\hline \multirow{2}{*}{ 4: Ø- /A- } & densu 'whale' & -densu & \multirow{2}{*}{$\begin{array}{l}\text { adensu 'whales' } \\
\text { aduku 'headgear' }\end{array}$} \\
\hline & duku 'headgear' & -duku & \\
\hline 5: +kinship & $\mathrm{V}-/ \varnothing$ & & \multirow{2}{*}{$\begin{array}{l}\text { A- / Ø-_-num } \\
\text { anuanum 'siblings' }\end{array}$} \\
\hline \multirow{2}{*}{ a. V-/ A- } & onua 'siblings' & -nua & \\
\hline & agya 'father' & -gya & agyanum 'fathers' \\
\hline \multirow{2}{*}{ b. Ø- / Ø- } & wofa 'uncle' & -wofa & \multirow{2}{*}{$\begin{array}{l}\text { wofanum 'uncles' } \\
\text { sewaanum 'aunts' }\end{array}$} \\
\hline & sewaa 'aunt' & -sewaa & \\
\hline \multirow{2}{*}{ 6: } & (O)-_-ni & & \multirow{5}{*}{$\begin{array}{l}\text { A-_-fos } \\
\text { asikafos 'rich person' } \\
\text { ahiafos 'poor people' } \\
\text { tikyafos 'teachers' } \\
\text { sogyafos 'soldiers' }\end{array}$} \\
\hline & osikani 'rich person' & -sika & \\
\hline a. & ohiani 'poor people' & -hia & \\
\hline \multirow{2}{*}{ b. Ø- / A-Identity/occupational } & tikyani 'teacher' & -tikya & \\
\hline & sogyani 'soldier' & -sogya & \\
\hline 7: & (O)-_-ni /-Ø & & \multirow{5}{*}{$\begin{array}{l}\mathrm{N} \text {-_-fos } \\
\text { nkramofos 'moslems' } \\
\text { nneduafos 'prisoners' } \\
\text { nsamanfos 'ghosts' } \\
\text { mpanyinfos 'elders' }\end{array}$} \\
\hline a $-\mathrm{ni} / \mathrm{N}-$ & okramoni 'moslem' & -kramo & \\
\hline a. -nI / N- & odeduani 'prisoner' & -dedua & \\
\hline \multirow{2}{*}{ b. - Ø / N- } & əsaman 'ghost' & -saman & \\
\hline & spanin 'elder’ & -panin & \\
\hline $\begin{array}{l}\text { 8: A- /- } \\
\text { (Derived) no plural }\end{array}$ & ado 'farming' & $-\mathrm{do}$ & \\
\hline (Derived) no plural & agoro 'game & -goro & \\
\hline 9: Mass & No singular & & $\mathrm{N}-/ \mathrm{V}-$ \\
\hline a. / N- & & $\begin{array}{l}\text {-frama } \\
\text {-bogya }\end{array}$ & $\begin{array}{l}\text { mframa 'air' } \\
\text { mmogya 'blood' }\end{array}$ \\
\hline & & -gya & egya 'fire' \\
\hline b. - / V- & & -woo & Ewoo 'honey' \\
\hline & & -sikyire & asikyire 'sugar' \\
\hline
\end{tabular}

\section{Theoretical Framework-Distributed Morphology}

The theory of Distributed Morphology is separationistic in nature in that it adopts the idea that the mechanisms, which are responsible for producing the form of syntactically and semantically complex expressions are separate from the mechanisms which produce the form of the corresponding phonological expressions. One of the core assumptions of $\mathrm{DM}$ is that syntax proper does not manipulate anything resembling lexical items, but rather, generates structures by manipulating and combining abstract roots and morphosyntactic features (taken from List 1, the "narrow" lexicon in figure 1) by means of various syntactic operations (such as movement and merger).

At the post-syntactic level of Morphological Structure
(MS), the arrangement and number of terminal nodes may be changed, for instance, by insertion of agreement nodes, feature copy, and morpheme insertion. Phonological matrixes are assigned to terminal nodes only after syntax at the level of Phonological Form (PF); this is referred to as "late insertion" (Marantz, 1995). Phonologically specified forms, Vocabulary items (VIs), are drawn from List 2, the Vocabulary. A VI is not merely a phonological string; rather, it also contains information about where that particular string may be inserted. Note that various VIs may compete for insertion in a given terminal node, with the most highly specified item that does not conflict in features with the specification of this terminal node winning the competition. Moreover, at PF, phonological readjustment rules may apply that change the phonological form of already inserted Vocabulary items (VIs) in certain syntactic contexts. 


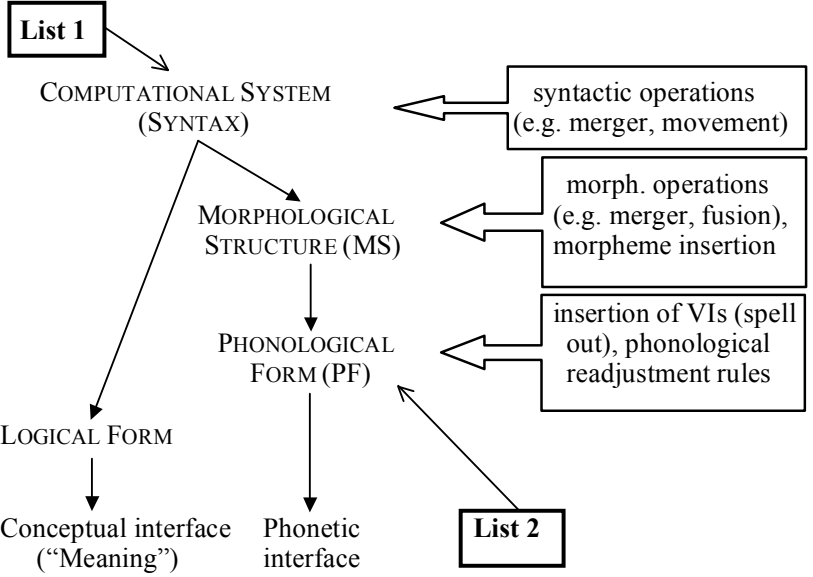

Figure 1. Structure of the grammar in DM.

\section{Analysis}

Table 2. Akan-Singular and Plural forms.

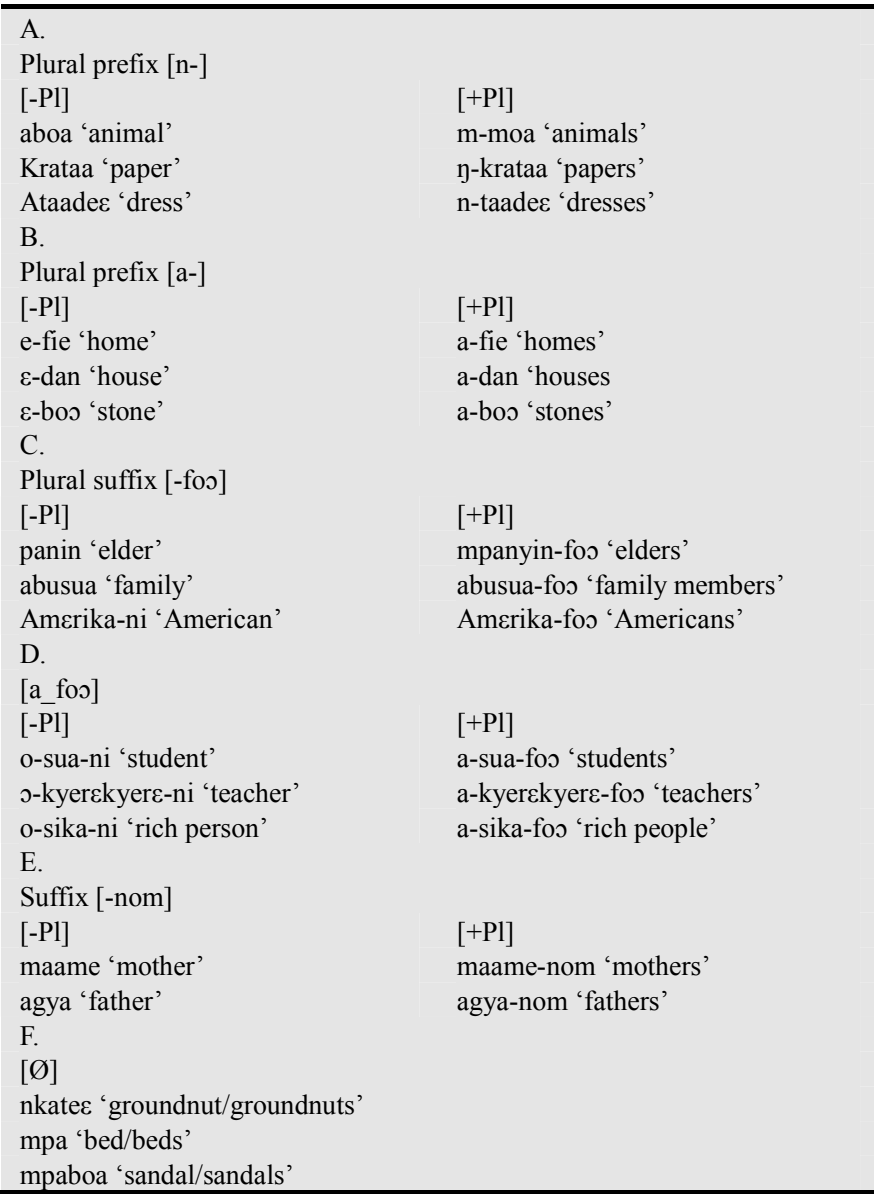

Based on the noun class system in Akan proposed by Bodomo and Marfo (2002) in section 1, the singular and plural affixes can be summarized as: Twi nouns usually have a prefix, which may be a vowel $e_{-}, \varepsilon-, a-, o_{-}, \nu_{-}$, or the consonant $m$ - or $n$ - and the suffix $-n i$ in the singular, and $a$-, $m$ - or $n$ - in the plural. Also suffixes -for, a for for nouns referring to humans, -nom for kingship nouns, and others $\varnothing$.

Vocabulary items (VI) for the plurals a $/ \mathrm{n}-/ \Leftrightarrow[\mathrm{pl}] /$ elsewhere

b $/ \mathrm{a}-/ \Leftrightarrow([\mathrm{pl}])$

c $/$-foo $/ \Leftrightarrow[\mathrm{pl}]$

d $/$ a $\_$foo/ $\Leftrightarrow[\mathrm{pl}]$

[+human]

e $/$-nom $/ \Leftrightarrow[\mathrm{pl}]$

[+Kinship]

f $/ \varnothing / \Leftrightarrow[\mathrm{pl}] /$ \{NKATE $\varepsilon ;$ MPA; MPABOA;... $\}$

In Distributed Morphology the above Vocabulary Items compete for insertion because they all mark the plural morpheme in Akan. The question we may ask ourselves is how do we insert the correct VI? DM proposes the Subset Principle, which specifies how VIs are inserted. 'The phonological exponent of a Vocabulary Item is inserted into a morpheme if the item matches all or a subset of the grammatical features specified in the terminal morpheme. Insertion does not take place if the Vocabulary Item contains features not present in the morpheme. Where several Vocabulary Items meet the conditions for insertion, the item matching the greatest number of features specified in the terminal morpheme must be chosen.' For example, the class of words in E will have the VI/-nom/ inserted because the context for the insertion is [+kinship] and /-nom/ is the most specified VI for such plurals-maame-nom 'mothers'.

Notwithstanding the subset principle, there are challenges as to which context does the plural morpheme /a-/ applies. We can suggest that /a-/ applies in the context of [-human] but that would not work because in Akan, there are words which have the [+human] feature and have /a-/ as the plural morpheme, for example a-hene 'kings'. Again, we may postulate an elsewhere for /a-/ because its occurrence cannot be predicted. Making such postulation will be misplaced in that the plural morpheme $/ \mathrm{n}-/$ has a wider occurrence compared to /a-/. Words that are borrowed into the Akan-Twi language have their plural formed with $/ \mathrm{n}-/$, for example bokiti 'bucket' and mmokiti 'buckets'. It must be mentioned that the surface form mmokiti is derived after the syntax, and morphology-vocabulary item $/ \mathrm{n}-/$ is inserted as prefix to the stem bokiti- $n$-bokiti. The phonology then applies to derive the correct output by the application of a phonological rule which changes $n$-bokiti to mmokiti.

The general question is which context does the Vocabulary Item /a-/ applies? The answer I may attempt to offer is that the vocabulary item /a-/ applies in some contexts as the default or the elsewhere morpheme. It happens to be the default in some contexts. An alternative analysis to this proposal is to list all the stems with VI /a-/ as the plural morpheme. The challenge with the alternative proposal is that we may have to also list all the words in D because those words also form plurals with /a-/ and /-foo/. This leads us to the next problem with Akan-Twi plurals.

The words in D use the prefix /a-/ and the suffix /-foo/ to indicate plural, and have the same context [+human] as the words in $\mathrm{C}$. What readily comes to mind with these words is to analyze them as circumfix, but words in $\mathrm{B}$ and $\mathrm{C}$ illustrate that this should not be considered as circumfix since either part can appear separately. The analysis we may apply here is 
to assume that /a-/ and /-foo/ target different nodes in this case two different number nodes. This means that the Vocabulary Items in B and C apply in a systematic fashion. The morphological operation fission, which has been applied to languages such as Tamazight Berber, will be used to analyse the Akan case at hand.

Fission occurs when Vocabulary Insertion does not stop after a single Vocabulary Item is inserted. Vocabulary Items accrete on the sister of the fissioned morpheme until all Vocabulary Items which can be inserted have been, or all features of the morpheme have been satisfactorily discharged. Noyer (1997) postulates that the features that condition the insertion of a Vocabulary Item come in two types. A Vocabulary Item primarily expresses certain features in its entry, but it may be said to secondarily express certain other features. This distinction corresponds (approximately) to the distinction between primary and secondary exponence (Carstairs, 1987). Only features which are primarily expressed by a Vocabulary Item are discharged by the insertion of that Item.

The application of fission to the Vocabulary Items listed above suggests that some vocabulary item must be inserted before others, in this case /a-/ and /-foo/. This is a challenge in Akan because we cannot predict which of the Vocabulary items should apply first. Any of the two can apply first and it will yield the same results. For example, if we assume that /a-/ must apply before /-foo/ the question then is what is the motivation for the application of /a-/ before /-foo/? We have not been able to establish the context for the insertion of /a-/. The alternative analysis is to assume /-foo/ as the primary express because its context is known and indeed morphemes with the two Vocabulary Items tend to be [+human] nouns. The secondary express then will be /a-/ which is inserted after the insertion of $/$-foo/. It must be mentioned that in fissioned morpheme, Vocabulary Items are no longer in competition for a single position-of-exponence or a single node, i.e. for the position of the morpheme itself. Rather, an additional positionof-exponence is automatically made available whenever a Vocabulary Item is inserted. This seems to be a plausible analysis because as we indicated above that /a-/ applies in some context as the default VI or the elsewhere morpheme.

For the fission analysis of the words in D some of the features of the Vocabulary Item list must be in parenthesis, and in this case is the /a-/. Parentheses are used to denote features which are secondarily expressed by a Vocabulary Item-/a-/, while ordinary features are those which primarily expresses are not parenthesized, for instance /-foo/. For example a morpheme $a$-sua-for 'students' has two affixes. The primary express VI /-foo/ is added first before the secondary express $\mathrm{VI} / \mathrm{a}-/$ is added.

\section{Conclusion}

The analysis of the Akan-Twi plurals is too complicated because we could not establish the context for the insertion of the Vocabulary Item /a-/. If we accept the fact that it is the default or elsewhere VI then what happens to the VI $/ n-/$ ? There should be a new assumption and a more concrete evidence to classify which of the two is the default. The alternative is to contradict the claim by Distributed Morphology that there is no lexicon by postulating the lexicalist idea that, in Akan, the plural prefix /a-/ has to be learned and stored in the lexicon. This is because its occurrence cannot be predicted.

Though we have been able to use fission to analyze the occurrence of /a-/ and /-foo/, within the class of words in C as in the word m-panyin-fos 'elders', how do we analyze the Vocabulary Items /n-/ and /-foo/? Fission would be the best way to analyzing those VIs. The challenge, here, is that $/ \mathrm{n}-/$ would have to be the secondary express. This brings to two VIs, which compete for the single position of the secondary exponence. The general question is how does Distributed Morphology analyze such a challenge? I leave this question for future research.

\section{References}

[1] Bodomo, A. B \& Marfo, C. O. (2002). "The Morphology of Noun Classes in Dagaare and Akan". Studi Linguistici $e$ Filologici Online 4.2 Dipartimento di Linguistica Universitàdi Pisa.

[2] Carstairs, A. (1987). Allomorphy in inflection. London: Croom Helm.

[3] Halle, M. (1997). "Distributed Morphology: Impoverishment and Fission". MITWPL 30: Papers at the Interface, edited by Benjamin Bruening, Yoonjung Kang and Martha McGinnis, 425-449. Cambridge: MITWPL.

[4] Halle, M. \& Marantz, A. (1993). "Distributed Morphology and the Pieces of Inflection". The view from building 20, ed. by S. Keyser and K. Hale, 111-76. Cambridge: MIT Press.

[5] Halle, M. and Marantz, A. (1994). "Some Key Features of Distributed Morphology". MIT working papers in linguistics 21: papers on phonology and morphology, ed. by A. Carnie, H. Harley and T. Bures, 275-88. Cambridge: MIT Working.

[6] Harley, H. \& Noyer, R. (1999). "State-of-the-Article: Distributed Morphology". Glot International 4.4, pp 3-9.

[7] Kiparsky, P. (1985). "Some consequences of lexical phonology". Phonology Yearbook 2: 85-138.

[8] Marantz, Alec. (1995). "A Late Note on Late Insertion". Explorations in Generative Grammar. Edited by Young-Sun Kim, et al., 396-413. Seoul: Hankuk Publishing Co.

[9] Mohanan, K. P. (1986). The Theory of Lexical Phonology. Dordrecht: Reidel.

[10] Noyer, R. (1997). Features, Positions and Affixes in Autonomous Morphological Structure. Garland Publishing, New York. Revised version of 1992 MIT Doctoral Dissertation. 